\title{
Nephrogenic Systemic Fibrosis
}

\author{
Neha Nainani Mandip Panesar \\ State University of New York at Buffalo, Buffalo, N.Y., USA
}

\section{Key Words}

Fibrosis · Gadolinium • Renal failure

\begin{abstract}
Nephrogenic systemic fibrosis is a recently diagnosed disease that occurs in patients with chronic kidney disease and acute renal failure. The patients develop skin thickening and fibrosis which is usually symmetrical, and typically of the upper and lower extremities. In some cases the progression is rapid leading to joint contractures confining the patient to a wheelchair. Systemic involvement may occur, leading to cardiomyopathy, pulmonary fibrosis, pulmonary hypertension, diaphragmatic paralysis and in severe cases death. The pathophysiology of the disease still remains unclear, but recent studies have demonstrated gadolinium deposits in tissues of patients diagnosed with nephrogenic systemic fibrosis. The prevalence of nephrogenic systemic fibrosis after exposure to gadolinium has been reported to be up to $12 \%$ in CKD stage 5 patients after a single exposure. No single treatment has been shown to be effective, although there are some patients shown to have improvement of their clinical symptoms with regaining of renal function especially after transplantation. In this article we review the current literature of this disease.
\end{abstract}

Copyright $\odot 2008$ S. Karger AG, Basel

\section{Introduction}

Nephrogenic fibrosing dermopathy is an acquired scleroderma-like fibrosing disorder of idiopathic etiology, only recently recognized, and develops in the setting of renal dysfunction. Cowper et al. $[1,2]$ were the first to describe this disorder in hemodialysis and renal transplant patients and since the clinical and pathologic findings were similar to scleromyxedema, they named the condition 'scleromyxedema-like disease in renal-dialysis patients' [3]. Later, the Center for Disease Control and Prevention issued a public health dispatch indicating that there was neither evidence of an infectious or toxic exposure and that no medical or technical triggers were found in this patient population, and the term 'fibrosing dermopathy of dialysis' was used. Since then, it has become apparent that some patients have never undergone dialysis and that there are distinct histological features distinguishing it from scleroderma, so that the term nephrogenic fibrosing dermopathy was coined [2]. However, several case reports have now identified cases in which the fibrosis has extended beyond the dermis and has involved subcutaneous tissues, striated muscles, diaphragm, pleura, pericardium, and the myocardium [4-6]. As such, this entity is now more appropriately referred to as nephrogenic systemic fibrosis (NSF).

\section{Clinical Features}

The hallmark of NSF is a thickening and hardening of the skin, usually symmetrical, and typically of the upper and lower extremities. The skin surface appears brawny and woody and can have a cobblestone or 'peau d'orange' texture to it [7]. These lesions, which can range from being papules and nodules, can either appear as distinct lesions or they can coalesce into sharply demarcated plaques with

\section{KARGER \\ Fax +4161306 1234 \\ E-Mail karger@karger.ch}

www.karger.com (c) 2008 S. Karger AG, Basel

0250-8095/09/0291-0001\$26.00/0

Accessible online at:

www.karger.com/ajn
Mandip Panesar

Erie County Medical Center, 462 Grider

Buffalo, NY 14215 (USA)

Tel. +1 716898 5492, Fax +1 7168983928

E-Mail mpanesar@buffalo.edu 
distinctive irregular edges resembling amoeboid projections [8]. They most commonly develop on the lower extremities between the ankles and thighs but have also been known to appear on the trunk and upper extremities. For reasons that are presently unknown, the face is usually spared [9]. The clinical course is progressive in most cases. It can be very painful, debilitating and sometimes fatal [5]. The patients may develop muscle weakness, bone pain, and joint contractures leading to severe disability.

A high degree of morbidity is associated with NSF since patients usually develop flexion contractures resulting in ambulatory dysfunction. The average age of onset is 48 years although cases from the pediatric and geriatric patient populations have been reported [10, 11]. The initial reports on NSF described only the cutaneous manifestations as it was thought that the disease was limited to the skin, but more recent cases have indicated that the disease process may have a strong systemic component as well. Ting et al. [5] were the first to describe a patient with skin manifestations of NSF who on autopsy was found to have extensive fibrosis and calcification of the diaphragm, psoas muscle, renal tubules and rete testis. Furthermore, Jimenez et al. [6] and Levine et al. [12] reported that the fibrotic process in NSF affects not only the dermis, but also the subcutaneous tissues, fascia, and other organs, including striated muscles, heart, and lungs $[4,5]$. These findings are suggestive that NSF may be a systemic fibrosing process.

There is no clinical diagnostic criterion and diagnosis is made by skin and muscle biopsy. The histopathology typically reveals an increase in dermal fibroblast-like cells in the presence of collagen remodeling, thickened collagen bundles, increased elastic fibers, and mucin deposition. Proliferation of dermal fibroblasts and dendritic cells is also evident.

The course of the disease is still not fully understood and complete resolution is very rare. Improvement has been seen in some patients with restoration of renal function either spontaneously or with transplantation [13]. In one case, there was some improvement of the cutaneous lesions after liver transplantation without a concurrent improvement of the underlying chronic renal disease [14].

\section{Etiology}

The etiology is presently unknown and is likely to be multifactorial. The most common factor identified in most patients is the presence of some form of acute or chronic renal injury with no cases till now reported in patients with normal kidney function. There is a lack of evidence supporting that hemodialysis and its related techniques and equipment used has any significant role to play in the development of NSF, although aromatic amines like 4,4'-methylenedianiline introduced into the bloodstream due to repeated heat and chemical sterilization of dialysis equipment have been implicated in some studies [15].

Patients with chronic kidney disease (CKD) and on hemodialysis are found to have an increased level of circulating immune complexes and antinuclear antibodies. About $30 \%$ of patients are positive for anticardiolipin antibodies $[16,17]$. This raises the possibility of some abnormal antigenic stimulation or exposure to nuclear superantigens leading to this erratic inflammatory response seen in NSF, but then the patients who developed NSF have never been studied for the presence of the antigens or antiphospholipid antibodies.

Cowper [2] identified that as many as $12 \%$ of patients diagnosed with NSF have either a hypercoagulable state such as factor V Leiden, hyperhomocysteinemia, protein C, protein S, and antithrombin III deficiency or a thrombotic event such as deep venous thrombosis, pulmonary emboli, and thrombosed arteriovenous fistula.

The current pathogenetic model for NSF supports the role of aberrantly functioning circulating fibrocytes coupled with the elaboration of fibrogenic factors. Immunohistochemical studies reveal that perhaps a dual positive CD34/procollagen spindle cell is the dominant cell type induced in NSF $[18,19]$. It is likely that a circulating fibrocyte is recruited, activated, and proliferated from the circulation to the dermis in response to a yet unidentified trigger $[20,21]$. The circulating fibrocyte is a leukocyte that uniquely expresses a combination of leukocyte and antigen presentation markers, as well as the capacity of synthesizing collagen I and III and transforming growth factor- $\beta$ (TGF- $\beta$ ) [18]. These cells are the main effector cells of the process of wound healing, angiogenesis and fibrosis [19]. The role of the fibrogenic factors was underlined by the increased expression of TGF- $\beta_{1}$ in affected skin and muscles of NSF patients, together with large numbers of CD68+/factor XIIIA+ dendritic cells in those tissues [6]. Accumulation of dermal mucin, an amorphous gelatinous substance composed primarily of hyaluronan and sulfated glycosaminoglycans, is one of the histopathological hallmarks of NSF [22]. TGF- $\beta_{1}$ is hypothesized to stimulate fibroblasts to produce elevated levels of glycosaminoglycans and hyaluronan [6]. 
Cowper et al. [23] proposed that a vascular procedure preceded the onset of NSF. In their study, $15 \%$ of patients had a nontransplant-related procedure while $48 \%$ had a transplant (renal or hepatic). When the placement of a dialysis central catheter or the creation of a fistula was included in the analysis, $90 \%$ of patients had one of these preceding the onset of NSF [2]. These findings suggest that some form of tissue injury or vascular injury is a prerequisite to the development of NSF.

Erythropoietin is known to have profibrogenic and proinflammatory effects via the upregulation of TGF- $\beta$ [24]. It has been shown to increase the number of circulating hematopoietic stem cells and endothelial progenitors by as much as $300 \%$ [25]. In vivo, it has been shown to trigger the fibrin-induced wound-healing response, similar to what is suspected to happen in NSF. Swaminathan et al. [25] tried to establish a correlation between the occurrence of NSF and erythropoietin therapy. In their study, they found that the incidence of NSF was much higher in patients receiving high-dose erythropoietin therapy [427 $\mathrm{U} / \mathrm{kg}$ per week (range, 66-1,195) vs. $198 \mathrm{U} / \mathrm{kg}$ per week (range, 14-720) among the controls] and also serum albumin concentrations were low and serum ferritin levels were high in patients with NSF. These results suggest that erythropoietin plays a direct role in the pathogenesis of NSF by the upregulation of the TGF- $\beta$ pathway and/or physiologically high erythropoietin levels may act as a surrogate marker for erythropoietin resistance and inflammatory states in patients who develop NSF. Further studies are needed to clarify this possibility.

There have been multiple reports describing gadolinium (Gd) as the implicating factor [26-29]. Grobner [26] was the first to propose a temporal association between the onset of NSF and exposure to gadolinium given as a contrast agent for patients undergoing MRI. In this study, 5 patients with end-stage renal disease (ESRD) on hemodialysis developed NSF within 2-4 weeks after MRI with gadodiamide. The average volume of gadodiamide used for MRI in these patients was $35 \mathrm{ml}(17.5 \mathrm{mmol})$ [28]. Broome et al. [27] published a case series in which 12 patients developed skin fibrosis within 1 week after gadodiamide administration. The odds ratio for development of NSF after gadodiamide exposure was found to be as high as 22.3 in this study. Cowper and colleagues [29] have recently published a study in which patients with ESRD were evaluated during an 18-month period. The incidence of NSF was 4.3/1,000 patient-years. Each radiologic study using gadolinium presented a $2.4 \%$ risk of NSF. The association between gadolinium exposure and NSF was highly significant.

Nephrogenic Systemic Fibrosis
Other similar studies have described 150 patients who developed NSF following the administration of gadolinium contrast agent (Gd-CA). It was found that more than $90 \%$ of these patients were administered the nonionic agent Omniscan (GE Healthcare AS, Oslo, Norway; gadodiamide) or OptiMARK (Mallinckrodt, St. Louis, Mo., USA; gadoversetamide) [30]. These studies raise the possibility that gadolinium-based contrast agents are unsafe in patients with renal failure since impaired kidney function can prevent the clearing of this contrast agent from the body. The half-life of gadolinium in patients with normal kidney function is approximately $90 \mathrm{~min}$, but in patients with advanced renal impairment, the elimination half-life can be prolonged to greater than $30 \mathrm{~h}$ [31]. Patients on hemodialysis may require three consecutive dialysis sessions to remove $97 \%$ of the administered dose of Gd-CA from the body [32]. Copper, zinc, iron and calcium ions in the body can substitute for the Gd ion, leading to the release of free gadolinium, a process termed transmetallation. The combination of decreased clearance and high level of Gd-chelate in patients with ESRD results in transmetallation of Gd-CA with the release of free gadolinium through replacement of the $\mathrm{Gd}^{3+}$ within the chelate molecule by body cations such as zinc or copper $[33,34]$. This has been shown in studies which have found free gadolinium deposition in the dermis of patients with NSF [35, 36]. Gadolinium in the free ion form is highly toxic and has been shown in animal studies to cause tissue necrosis and fibrosis. The study conducted by Sieber et al. [37] has suggested that the release of $\mathrm{Gd}^{3+}$ from its chelate subsequently leads to its deposition in the skin which can cause NSF, and there was no additional evidence to support a role for the depletion of endogenous metal ions to play a causative role. Gadodiamide and gadoversetamide were injected into rats in doses of 0,5 and $10 \%$ (excess) content of Gd-free ligand. The animals were then evaluated for the presence and concentration of gadolinium, zinc, and copper in the skin, liver, femur and serum. Skin lesions that were consistent with NSF and had the highest amount of gadolinium were found in those animals that received compounds with the highest risk for the release of $\mathrm{Gd}^{3+}$ ions, i.e. those contrast agents that had $0 \%$ excess ligand. Similarly, no skin lesions suggestive of NSF and lower gadolinium concentrations were seen in those animals that were injected with the contrast agent that had the highest risk for generating a depletion of endogenous metal ions, i.e. agents that had $10 \%$ free ligand [37]. Therefore, it has been hypothesized that the free gadolinium ion deposited in the

Am J Nephrol 2009;29:1-9 


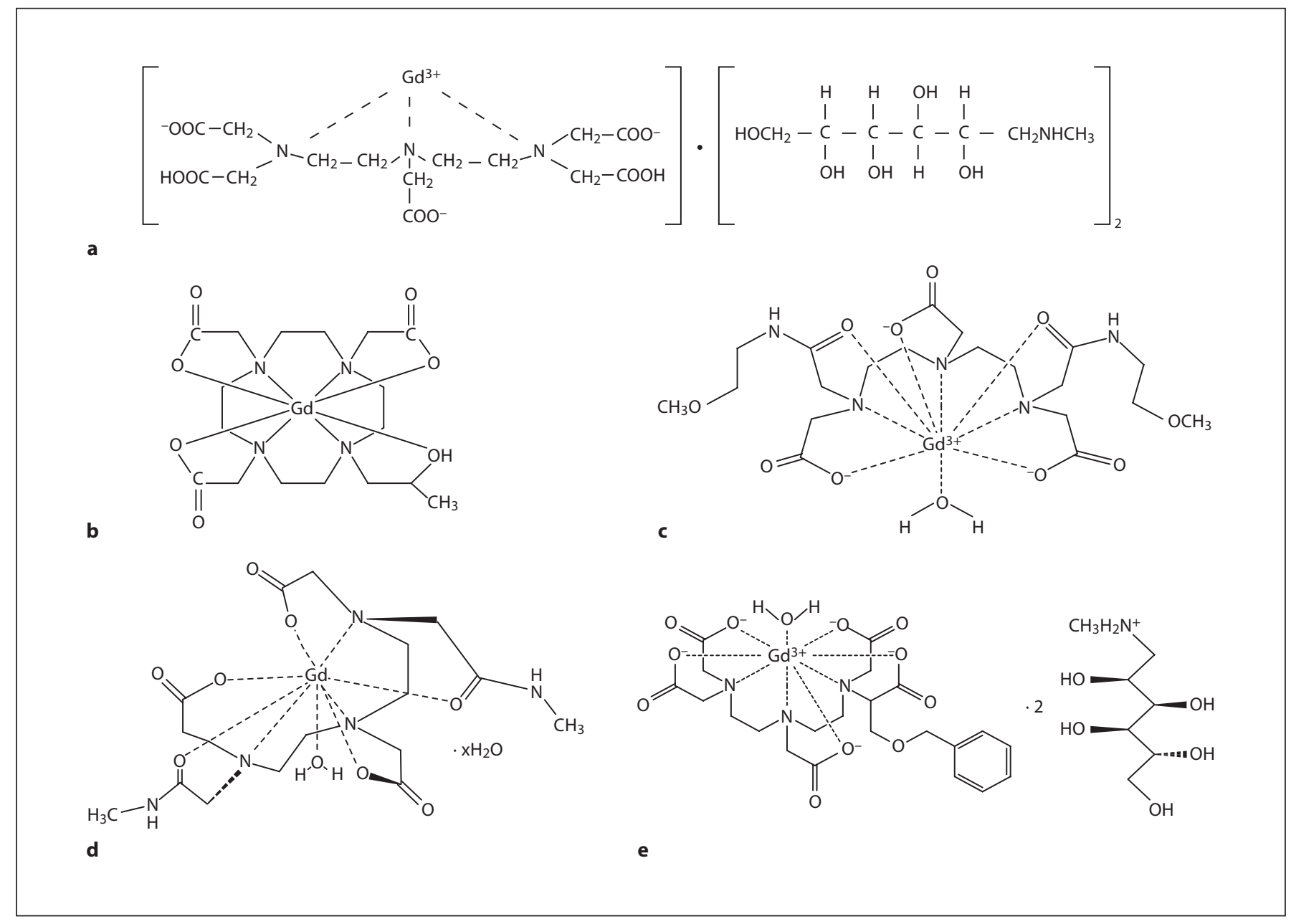

Fig. 1. Chemical structures of the five FDA-approved intravenous Gd agents, as provided in the manufacturers' product inserts. a Magnevist. b ProHance. c OptiMARK. d Omniscan. e MultiHance [from 42].

Table 1. Chemical properties of available extracellular gadolinium contrast agents

\begin{tabular}{|c|c|c|c|c|c|c|c|}
\hline & Structure & Ionicity & $\begin{array}{l}\text { Osmo- } \\
\text { larity }\end{array}$ & $\begin{array}{l}\text { Thermodynamic } \\
\text { stability constant }\end{array}$ & $\begin{array}{l}\text { Conditional } \\
\text { stability }\end{array}$ & $\begin{array}{l}\text { Amount of } \\
\text { excess chelate }\end{array}$ & $\begin{array}{l}\text { Clearance } \\
\mathrm{T} 1 / 2, \mathrm{~h}\end{array}$ \\
\hline $\begin{array}{l}\text { Magnavist gadopentetate } \\
\text { demeglumine Gd-DTPA }\end{array}$ & linear & ionic & 1,960 & 22.1 & 18.1 & 0.4 & renal 1.6 \\
\hline $\begin{array}{l}\text { ProHance gadoteridol } \\
\text { Gd-HO-DO3A }\end{array}$ & $\begin{array}{l}\text { macro- } \\
\text { cyclic }\end{array}$ & $\begin{array}{l}\text { non- } \\
\text { ionic }\end{array}$ & 630 & 23.8 & 17.1 & 0.23 & renal 1.57 \\
\hline $\begin{array}{l}\text { Omniscan gadodiamide } \\
\text { Gd-DTPA-BMA }\end{array}$ & linear & $\begin{array}{l}\text { non- } \\
\text { ionic }\end{array}$ & 789 & 16.9 & 14.9 & 12 & renal 1.3 \\
\hline $\begin{array}{l}\text { OptiMARK gadoversetamide } \\
\text { Gd-DTPA-BMEA }\end{array}$ & linear & $\begin{array}{l}\text { non- } \\
\text { ionic }\end{array}$ & 1,110 & 16.6 & 15 & 28.4 & renal 1.73 \\
\hline $\begin{array}{l}\text { MultiHance gadobenate } \\
\text { demeglumine Gd-BOPTA }\end{array}$ & linear & ionic & 1,970 & 22.6 & 18.4 & none & $\begin{array}{l}96 \% \text { renal, } 4 \% \\
\text { hepatic } 1-2 \mathrm{~h}\end{array}$ \\
\hline
\end{tabular}


skin may act as a trigger for recruiting the circulating fibrocytes discussed previously [18].

There is now concern about whether the chemical structure of the contrast agent is important in the development of NSF. There are five Gd-CA available for clinical use. The chemical structure and chemical properties of these agents are shown in table 1 and figure 1 . They are all chelates containing the $\mathrm{Gd}^{3+}$. The molecules are configured in a linear or cyclic form and they are available as an ionic or nonionic preparation. The macrocyclic chelates, such as gadoteric acid (Gd-DOTA; Dotarem, Guerbet, Paris, France), bind $\mathrm{Gd}^{3+}$ more tightly than linear chelates, such as gadodiamide (Omniscan) or gadopentetate dimeglumine (Magnevist, Bayer Healthcare Pharmaceuticals, Wuppertal, Germany). The key to understanding which gadolinium agent is toxic to the body is in the stability of the chelate molecules which is expressed in terms of the thermodynamic stability constant, conditional stability and kinetic stability (dissociation half-life under very acidic conditions) [38]. Some gadolinium preparations have excess chelate to prevent formation of free $\mathrm{Gd}^{3+}$ in the solution. The presence of this excess chelate indicates low stability of the preparation. Nonionic linear gadolinium chelates, which have the lowest thermodynamic and constant stability values, and the highest amount of excess chelate in comparison to the other types of Gd-CA are the least stable and most prone to transmetallation $[32,38-40,42]$ and should be avoided in patients with renal insufficiency.

The prevalence of NSF after exposure to gadodiamide has been reported to be between 3 and $7 \%$ in patients with reduced renal function in several different studies $[27,29$, $41,43-45]$. In a well-defined cohort of CKD stage 5 patients (GFR $<15 \mathrm{ml} / \mathrm{min} / 1.73 \mathrm{~m}^{2}$ ), single exposure to gadodiamide was associated with a $12 \%$ (95\% CI: 6-21) NSF prevalence, whereas the NSF prevalence was 36\% (95\% CI: 18-59) after two exposures [46]. The prevalence of NSF due to exposure to the other less stable agents, gadopentetate dimeglumine and gadoversetamide, is unknown. Those contrast agents that are based on the DOTA ligand or the DTPA ligand have not yet been reported to have a cause and effect relationship to the development of NSF [47].

Sadowski et al. [41] have analyzed the risk factors associated with development of NSF in patients who were exposed to gadolinium contrast. Covariates studied were serum creatinine, serum albumin, hemoglobin, serum $\mathrm{pH}$, red cell size/morphology, serum bicarbonate level, C-reactive protein level, antinuclear antibody titer, number of proinflammatory events per patient and number of contrast-enhanced MRI exams. Proinflammatory events in the study included a broad group of conditions in which the body had sustained major tissue injury through surgery, vascular complications or systemic infection. The results showed that 4,236 patients underwent contrast-enhanced MRI of whom 393 had estimated GFR (eGFR) $<60 \mathrm{ml} / \mathrm{min} / 1.73 \mathrm{~m}^{2}$ and $3,843 \mathrm{had}$ eGFR $>60 \mathrm{ml} / \mathrm{min} / 1.73 \mathrm{~m}^{2}$. Of the patients with eGFr $<60 \mathrm{ml} /$ $\min / 1.73 \mathrm{~m}^{2}, 131 \mathrm{had}$ a proinflammatory event and were hospitalized and only 6 of these patients developed NSF. This resulted in a 1-year NSF incidence of $4.6 \% /$ hospitalized patient with eGFR $<60 \mathrm{ml} / \mathrm{min} / 1.73 \mathrm{~m}^{2}$ and having some form of proinflammatory condition [42]. The risk increased with the degree of renal insufficiency, number of proinflammatory events and the number of contrastenhanced MRI examinations. The individual GFR of the 6 cases that developed NSF have not been given in the study; however, the authors described 13 patients who developed NSF and had been exposed over a period of 4 years. Out of these 13 patients, 11 patients had CKD stage 4 or 5 (some were on dialysis) and only 2 patients were labeled as CKD stage 2 or 3 . These 2 patients were found to have acute renal failure. Thus, patients with ESRD on dialysis or those with eGFR $<30 \mathrm{ml} / \mathrm{min} / 1.73 \mathrm{~m}^{2}$ are at high risk of developing NSF when exposed to gadolinium contrast with an ongoing proinflammatory state. In another study, 190 patients with varying stages of CKD and exposed to gadolinium contrast were retrospectively studied for development of NSF. Eighteen of these patients (approximately 10\%; 95\% CI: 6-15\%) were diagnosed with NSF within a mean follow-up period of 29 months (range 16-43 months). All 18 cases had CKD stage 5 at the time of their gadodiamide exposure. The prevalence of NSF among patients with CKD stage 5 at exposure $(n=102)$ was $18 \%$ (95\% CI: $11-27 \%)$. No cases were seen among 88 gadodiamide-exposed patients who had milder degrees of renal insufficiency (prevalence $0 \%$, 95\% CI: 0-4\%) [48].

About $90 \%$ of the NSF cases reported to the International Registry of NSF at Yale University are in patients who are on dialysis [49]. Another study showed that $80 \%$ of NSF cases were found in patients on dialysis and another $10 \%$ were either CKD stage 4 or 5 and the remaining $10 \%$ had acute kidney injury. No patients with an eGFR $>30 \mathrm{ml} / \mathrm{min} / 1.73 \mathrm{~m}^{2}$ were identified [50]. Peritoneal dialysis poses an even higher risk for the development of NSF. One study has shown that attack rates among peritoneal dialysis patients were 10 times higher than among patients on hemodialysis [51]. The incidence and prevalence of the disease are difficult to ascertain. 
Table 2. Differential diagnosis of nephrogenic fibrosing dermatopathy

\author{
Scleromyxedema \\ Eosinophilia-myalgia syndrome \\ Eosinophilic fasciitis (Shulman syndrome) \\ Systemic sclerosis/morphea \\ Porphyria cutanea tarda \\ Fibroblastic rheumatism \\ Spanish toxic oil syndrome \\ Vinyl chloride exposure \\ $\beta$-Microglobulin amyloidosis \\ Dermatofibrosarcoma protuberans
}

NSF affects about $4 \%$ of patients with advanced CKD or ESRD $[27,44]$. In another study, the yearly incidence was calculated at 4.3 cases/1,000 patients in a stable outpatient ESRD population treated at three different centers [29]. No study till now has yet been conducted to assess the relative prevalence of NSF among patients with different stages of CKD that have been exposed to gadolinium-containing contrast agents. Thus, it is impossible to determine at what stage of CKD the use of gadoliniumcontaining contrast agents is safe, but the general trend from all reported cases is that patients with $\mathrm{eGFr}<30 \mathrm{ml} /$ $\min / 1.73 \mathrm{~m}^{2}$ and ESRD are at the highest risk. Almost all cases of NSF have been associated with the administration of gadolinium-containing contrast media. However, all patients who receive gadolinium and have renal impairment do not develop NSF. Studies have suggested additional risk factors which include medications that could cause transmetallation of gadolinium, high doses of erythropoietin [21], concomitant medical conditions, including acidosis, recent surgery [2], hepatic disease, hypercoagulability [15] and proinflammatory processes [41].

In light of current evidence, the FDA has issued the following recommendations [52]. First, we must identify patients at risk of developing NSF which includes patients with acute or chronic severe renal insufficiency (glomerular filtration rate $<30 \mathrm{ml} / \mathrm{min} / 1.73 \mathrm{~m}^{2}$ ) or acute renal dysfunction due to the hepatorenal syndrome or in the perioperative liver transplantation period. Second, it is imperative to avoid the use of gadolinium-based contrast agent in patients with known risk factors for developing NSF unless the diagnostic information is essential and cannot be obtained with a non-contrast-enhanced MRI or other diagnostic procedures. Third, if a GBCA has to be administered, avoid exceeding the recommended GBCA dose stated in the product label and allow a suf- ficient period of time for elimination of the agent from the body prior to any GBCA readministration. Furthermore, in patients receiving hemodialysis, prompt hemodialysis should be done after administration of a GBCA since hemodialysis enhances GBCA elimination from the body. Lastly, patients on peritoneal dialysis should perform more frequent manual exchanges or additional automated peritoneal dialysis cycles for at least $48 \mathrm{~h}$ after administration.

The FDA recommendation should not preclude nephrologists from using gadolinium in CKD patients but rather limit its use in high-risk populations. It would be impossible to completely ban the use of gadolinium in CKD patients since the use of contrast-enhanced MRI is extensively used in nephrology to help diagnose renal artery stenosis, renal malignancies, and osteomyelitis. The alternative to gadolinium is to use intravenous contrast. One would prefer to use intravenous contrast, especially if the imaging is comparable, in patients on dialysis since the risk of developing contrast-induced nephropathy is clinically of no importance in this particular population. The clinical dilemma arises in situations where gadolinium-enhanced imaging would be superior to that of intravenous contrast to deliver the clinical information needed and where the patient is on dialysis. Current FDA guidelines would deter the nephrologist from the use of gadolinium. Although intravenous contrast would be a reasonable alternative, it is associated with the risk of anaphylaxis and the complication of radiation exposure to the patient. The other potential clinical predicament occurs in patients with moderate CKD. The true risk of developing NSF after gadolinium in this population is not clearly known at the moment, while the risk of developing contrast nephropathy can be between 10 and 20\% [53]. Choosing the most clinically appropriate imaging study for this particular patient population will have to be done bearing in mind the risks and benefits of the two available contrast agents. Clinical data comparing the long-term safety of these agents in CKD is currently limited to make any formal recommendations.

\section{Differential Diagnosis}

The differential diagnosis of NSF is quite broad and includes several sclerosing and mucin deposition disorders some of which have been shown in table 2. NSF presents as painful erythematous or skin-colored papules or nodules. Sometimes, when these nodules coalesce to form indurated plaques, differentiation from other sys- 
Table 3. Differences between NSF and scleroderma

\begin{tabular}{|c|c|c|}
\hline & NSF & Scleroderma \\
\hline Major associated disease & renal failure & multiple myeloma \\
\hline Symptoms & $\begin{array}{l}\text { skin plaques; joint contractures with } \\
\text { restriction of mobility; kidney heart and } \\
\text { lung dysfunction; diaphragmatic paralysis }\end{array}$ & $\begin{array}{l}\text { skin plaques; leonine facies; restrictive or obstructive } \\
\text { pulmonary dysfunction; cardiovascular abnormalities; } \\
\text { proximal muscle weakness; esophageal dysmotility }\end{array}$ \\
\hline Distribution & trunk and extremities; face is spared & trunk and extremities; face is usually involved \\
\hline Paraproteinemia & no & yes \\
\hline Systemic involvement & yes but few & yes \\
\hline \multicolumn{3}{|l|}{ Histological findings } \\
\hline Interstitial mucin & yes & yes \\
\hline Inflammatory cells & no & yes \\
\hline
\end{tabular}

temic sclerosing conditions becomes difficult. All patients with NSF are found to have some degree of renal insufficiency and many may be on dialysis. Laboratory tests such as peripheral eosinophils (high in eosinophilic fasciitis and toxic fibrosing disorders), long-acting thyroid stimulator antibodies (seen in pretibial myxedema) and autoantibodies (anti-Scl-70 or anticentromere antibodies in systemic sclerosis) can help in making the diagnosis. From the list of potential differential diagnoses, scleromyxedema is the most difficult to differentiate (table 3). Patients with scleromyxedema develop indurated plaques on the face, while facial lesions are generally spared in patients with NSF. A monoclonal paraprotein, usually of the IgG lambda type, is often present in scleromyxedema but is absent in patients with NSF. The histology also helps differentiating the two diseases. There is a significant amount of inflammatory infiltrate and a lot of mucin deposits seen in biopsies from patients with scleromyxedema which is not seen in NSF [54]. Thus, a thorough history and physical exam coupled to a comprehensive laboratory evaluation and a tissue biopsy can help in making an accurate diagnosis.

\section{Treatment}

We have only begun to understand the disease process and as expected there is no single treatment that has been shown to be effective. High-dose intravenous immunoglobulin [55], extracorporeal photopheresis [56], immune suppressive medications (oral/topical steroids [57, 58], calcipotriene ointment [59], cyclophosphamide [60], cyclosporine, thalidomide, interferon- $\alpha$ ), psoralen, and ultraviolet light [61] have been reported to provide some benefit, but evidence is derived from either individual case reports or small case series and must be interpreted with caution. There is accumulating evidence in support of renal transplantation as a safe and effective treatment option where patients have reported improvement of their symptoms after transplantation.

\section{Conclusion}

NSF is characterized by a hardening and thickening of the skin which over time results in flexion contractures of the involved joints. Although no known mortality has yet been established, patients usually have a significant degree of ambulatory dysfunction. Our knowledge of this debilitating disorder is limited at the moment and conclusions and suggestions for treatment, of which there are none, are derived from either case reports or small case series. There is accumulating evidence that gadolinium may play a role and recommendations are to avoid use of GBCA in patients with moderate to severe renal insufficiency. We still have a lot to learn about this disorder especially with regard to its natural course, prognosis, and especially its cause, pathogenesis, and treatment. Although it still remains an underreported condition, early recognition and diagnosis will be paramount in achieving a better understanding of this disease. 


\section{References}

-1 Cowper SE, Robin HS, Steinberg SM, Su LD, Gupta S, LeBoit PE: Scleromyxoedema-like cutaneous diseases in renal-dialysis patients. Lancet 2000;356:1000-1001.

2 Cowper SE: Nephrogenic fibrosing dermopathy: the first 6 years. Curr Opin Rheumatol 2003;15:785-790.

-3 McNeill AM, Barr RJ: Scleromyxedema-like fibromucinosis in a patient undergoing hemodialysis. Int J Dermatol 2002;41:364-367

4 Gibson SE, Farver CF, Prayson RA: Multiorgan involvement in nephrogenic fibrosing dermopathy: an autopsy case and review of the literature. Arch Pathol Lab Med 2006; 130:209-212.

5 Ting WW, Stone MS, Madison KC, Kurtz K: Nephrogenic fibrosing dermopathy with systemic involvement. Arch Dermatol 2003; 139:903-906

-6 Jimenez SA, Artlett CM, Sandorfi N, et al: Dialysis-associated systemic fibrosis (nephrogenic fibrosing dermopathy): study of inflammatory cells and transforming growth factor beta 1 expression in affected skin. Arthritis Rheum 2004;50:2660-2666.

7 Scheinfeld N: Nephrogenic fibrosing dermopathy: a comprehensive review for the dermatologist. Am J Clin Dermatol 2006;7: 237-247.

-8 Mackay-Wiggan JM, Cohen DJ, Hardy MA, Knobler EH, Grossman ME: Nephrogenic fibrosing dermopathy (scleromyxedema-like illness of renal disease). J Am Acad Dermatol 2003;48:55-60.

9 Hamilton-Persaud K, Ezell LD, Macklin JG: Nephrogenic fibrosing dermopathy/nephrogenic systemic fibrosis. Nephrol Nurs J 2007; 34:283-287.

10 Jain SM, Wesson S, Hassanein A, Canova E, Hoy M, Fennell RS, Dharnidharka VR: Nephrogenic fibrosing dermopathy in pediatric patients. Pediatr Nephrol 2004;19:467470.

11 Jan F, Segal JM, Dyer J, LeBoit P, Siegfried E, Frieden IJ: Nephrogenic fibrosing dermopathy: two pediatric cases. J Pediatr 2003;143: 678-681.

-12 Levine JM, Taylor RA, Elman LB, Bird SJ, Lavi E, Stolzenberg ED, et al: Involvement of skeletal muscle in dialysis-associated systemic fibrosis (nephrogenic fibrosing dermopathy). Muscle Nerve 2004;30:569-577.

13 Panesar M, Barone G, Kumar J, Kimball S, Gokden N, Abul-Ezz S: Clinical and pathological features of nephrogenic fibrosing dermopathy: improvement after kidney transplantation in three patients (abstract). J Am Soc Nephrol 2005; 16(abstract issue): 691A.

14 Chiu H, Wells G, Carag H, Canova E, Firpi RJ: Nephrogenic fibrosing dermopathy: a rare entity in patients awaiting liver transplantation. Liver Transpl 2004;10:465-466.
15 Do Luu HM, Hutter JC: Pharmacokinetic modeling of $4,4^{\prime}$-methylenedianiline released from reused polyurethane dialyzer potting materials. J Biomed Mater Res 2000; 53(3):276-286.

16 Perez GO, Glasson P, Favre H, et al: Circulating immune complexes in regularly dialyzed patients with chronic renal failure. Am J Nephrol 1984;4(4):215-221.

17 Valeri A, Joseph R, Radhakrishnan J: A large prospective survey of anti-cardiolipin antibodies in chronic hemodialysis patients. Clin Nephrol 1999;51(2):116-121.

-18 Ortonne N, Lipsker D, Chantrel F, Boehm N, Grosshans E, Cribier B: Presence of $\mathrm{CD} 45 \mathrm{RO}+\mathrm{CD} 34+$ cells with collagen synthesis activity in nephrogenic fibrosing dermopathy: a new pathogenic hypothesis. $\mathrm{Br} \mathrm{J}$ Dermatol 2004;150(5):1050-1052.

19 Quan TE, Cowper S, Wu SP, Bockenstedt LK, Bucala R: Circulating fibrocytes: collagensecreting cells of the peripheral blood. Int J Biochem Cell Biol 2004;36:598-606.

20 Haroon ZA, Amin K, Jiang X, Arcasoy MO: A novel role for erythropoietin during fibrin-induced wound-healing response. Am J Pathol 2003;163:993-1000.

-21 Swartz RD, Crofford LJ, Phan SH, Ike RW, Su LD: Nephrogenic fibrosing dermopathy: a novel cutaneous fibrosing disorder in patients with renal failure. Am J Med 2003;114: 563-572.

22 Edward M, Fitzgerald L, Thind C, Leman J, Burden AD: Cutaneous mucinosis associated with dermatomyositis and nephrogenic fibrosing dermopathy: fibroblast hyaluronan synthesis and the effect of patient serum. Br J Dermatol 2007;156:473-479.

23 Cowper SE: Nephrogenic systemic fibrosis: the nosological and conceptual evolution of nephrogenic fibrosing dermopathy. Am J Kidney Dis 2005;46:763-765.

24 LeBoit PE: What nephrogenic fibrosing dermopathy might be. Arch Dermatol 2003;139: 928-930.

25 Swaminathan S, Ahmed I, McCarthy JT, Albright RC, Pittelkow MR, Caplice NM, Griffin MD, Leung N: Nephrogenic fibrosing dermopathy and high-dose erythropoietin therapy. Ann Intern Med 2006;145:234235.

26 Grobner T: Gadolinium - a specific trigger for the development of nephrogenic fibrosing dermopathy and nephrogenic systemic fibrosis. Nephrol Dial Transplant 2006;21: 1104-1108.

27 Broome DR, Girguis MS, Baron PW, Cottrell AC, Kjellin I, Kirk GA: Gadodiamide associated nephrogenic systemic fibrosis: why radiologists should be concerned. AJR Am J Roentgenol 2007;188:586-592.
28 Khurana A, Runge VM, Narayanan M, Greene JF, Nickel AE: Nephrogenic systemic fibrosis: a review of 6 cases temporally related to gadodiamide injection (omniscan). Invest Radiol 2007;42:139-145

29 Deo A, Fogel M, Cowper SE: Nephrogenic systemic fibrosis: a population study examining the relationship of disease development to gadolinium exposure. Clin J Am Soc Nephrol 2007;2:264-267.

30 Thomsen HS: Nephrogenic systemic fibrosis: a serious late adverse reaction to gadodiamide. Eur Radiol 2006;16:2619-2621.

-31 Idée JM, Port M, Raynal I, Schaefer M, Le Greneur S, Corot C: Clinical and biological consequences of transmetallation induced by contrast agents for magnetic resonance imaging: a review. Fundam Clin Pharmacol 2006;20:563-576.

32 Morcos SK, Thomsen HS, Webb JAW, et al: Dialysis and contrast media. Eur Radiol 2002;12:3026-3030.

33 Mann JS: Stability of gadolinium complexes in vitro and in vivo. J Comput Assist Tomogr 1993;17(suppl 1):S19-S23.

- 34 Idée JM, Port M, Raynal I, Schaefer M, Le Greneur S, Corot C: Clinical and biological consequences of transmetallation induced by contrast agents for magnetic resonance imaging: a review. Fundam Clin Pharmacol 2006;20:563-576.

- 35 Boyd AS, Zic JA, Abraham JL: Gadolinium deposition in nephrogenic fibrosing dermopathy. J Am Acad Dermatol 2007;56:27-30.

36 High WA, Ayers RA, Chandler J, Zito G, Cowper SE: Gadolinium is detectable within the tissue of patients with nephrogenic systemic fibrosis. J Am Acad Dermatol 2007;56: 21-26.

37 Sieber M, Walter J, Frenzel T, Weinmann HJ, Pietsch H: Gadolinium deposition or depletion of endogenous ions - what could be the trigger for nephrogenic systemic fibrosis? J Am Soc Nephrol 2007; 18(abstract issue): $422 \mathrm{~A}$.

38 Idée JM, Port M, Raynal I, Schaefer M, Le Greneur S, Corot C: Clinical and biological consequences of transmetallation induced by contrast agents for magnetic resonance imaging: a review. Fundam Clin Pharmacol 2006;20:563-576.

-39 Kuo PH, Kanal E, Abu-Alfa AK, Cowper SE: Gadolinium-based MR contrast agents and nephrogenic systemic fibrosis. Radiology 2007;242:647-649.

-40 Galan A, Cowper SE, Bucala R: Nephrogenic systemic fibrosis (nephrogenic fibrosing dermopathy). Curr Opin Rheumatol 2006; 18:614-617.

-41 Sadowski E, Bennett L, Chan M, Wentland A, Garrett A, Garrett R, Djamali A: Nephrogenic systemic fibrosis: risk factors and incidence estimation. Radiology 2007;243:148157. 
42 Lin SP, Brown JJ: MR contrast agents: physical and pharmacologic basics. J Magn Reson Imaging 2007;25:884-899.

-43 Collidge TA, Thomson PC, Mark PB, Traynor JP, Jardine AG, Morris ST, Simpson K, Roditi GH: Gadolinium-enhanced MR imaging and nephrogenic systemic fibrosis: retrospective study of a renal replacement therapy cohort. Radiology 2007;245:168-175.

-44 Marckmann P, Skov L, Rossen K, Dupont A, Damholt MB, Heaf JG, Thomsen HS: Nephrogenic systemic fibrosis: suspected etiological role of gadodiamide used for contrast-enhanced magnetic resonance imaging. J Am Soc Nephrol 2006;17:2359-2362.

-45 Lauenstein TC, Salman K, Morreira R: Nephrogenic system fibrosis: center case review. J Magn Reson Imaging 2007;26:11981203.

-46 Rydahl C, Thomsen HS, Marckmann P: High prevalence of nephrogenic systemic fibrosis in renal failure patients exposed to gadodiamide, a gadolinium (Gd)-containing magnetic resonance contrast agent. Invest Radiol 2008;43:141-144.

-47 Thomsen HS, Marckmann P: Extracellular Gd-CA: differences in prevalence of NSF. Eur J Radiol 2008;66:180-183.
48 Wington CD, Kelly B, Oto A, Jesse M, Aristimuno P, Ernst R, Chaljub G: Gadoliniumbased contrast exposure, nephrogenic systemic fibrosis, and gadolinium detection in tissue. AJR Am J Roentgenol 2008;190: 1060-1068.

49 Cowper SE: Nephrogenic fibrosing dermatopathy. http://www.icnfdr.org. (accessed April 27, 2007).

50 Abu-Alfa A: The impact of NSF on the care of patients with kidney disease. J Am Coll Radiol 2008;5:45-52.

51 Cheng S, Abramova L, Saab G, Turabelidze G, Patel P, Hess T, Kallen A, Jhung M: Nephrogenic fibrosing dermatopathy associated with exposure to gadolinium-containing contrast agents - St Louis, Missouri, 20022006. Morbid Mortal Weekly Rep 2007;56: 137-141.

52 FDA/CDER/Drug Information Page. United States Food and Drug Administration website.http://www.fda.gov/cder/drug/infopage/gcca/qa.htm (accessed February 22, 2008).

53 Finn WF: The clinical and renal consequences of contrast-induced nephropathy. Nephrol Dial Transplant 2006;21:i2-i10.

54 Daram SR, Cortese CM, Bastani B: Nephrogenic fibrosing dermopathy/nephrogenic systemic fibrosis: report of a new case with literature review. Am J Kidney Dis 2005;46: 754-759.
55 Chung HJ, Chung KY: Nephrogenic fibrosing dermopathy: response to high-dose intravenous immunoglobulin. Br J Dermatol 2004;150:596-597.

56 Gilliet M, Cozzio A, Burg G, Nestle FO: Successful treatment of three cases of nephrogenic fibrosing dermopathy with extracorporeal photopheresis. Br J Dermatol 2005; 152:531-536.

57 Chiu H, Wells G, Carag H, Canova E, Firpi RJ: Nephrogenic fibrosing dermopathy: a rare entity in patients awaiting liver transplantation. Liver Transpl 2004;10:465-466.

58 Perazella MA, Ishibe S, Perazella MA, Reilly RF: Nephrogenic fibrosing dermopathy: an unusual skin condition associated with kidney disease. Semin Dial 2003;16:276-279.

-59 Mackay-Wiggan JM, Cohen DJ, Hardy MA, Knobler EH, Grossman ME: Nephrogenic fibrosing dermopathy (scleromyxedema-like illness of renal disease). J Am Acad Dermatol 2003;48:55-60.

60 Tan A, Tan S, Lian T, Ng S: A case of nephrogenic fibrosing dermopathy. Ann Acad Med Singapore 2004;33:527-529.

61 Wahba IM, White K, Meyer M, Simpson EL: The case for ultraviolet light therapy in nephrogenic fibrosing dermopathy - report of two cases and review of the literature. Nephrol Dial Transplant 2007;22:631-636. 